\title{
PENGARUH LIFESTYLE TERHADAP KEPUTUSAN PEMBELIAN PADA SEPATU MEREK FLADEO DI BASKO GRAND MALL PADANG
}

\author{
Rido Kurniawan, Febsri Susanti \\ Sekolah Tinggi Ilmu Eknomi "KBP" \\ febsrisusanti@akbpstie.ac.id
}

\begin{abstract}
This study aims to determine whether there is influence on the purchase decision of Fladeo products. The object chosen by the researchers is Basko Grand Mall. Data Type is the primary data. The data is taken directly from Basko Grand Mall. While the sample of this study is determined by Accidental Sampling. Data analysis techniques used are validity test, reliability test, descriptive analysis, classical assumption test, simple linear regression analysis, $T$ test and determinant coefficient $\left(R^{2}\right)$ using SPSS program. Based on the results of hypothesis testing found that independent variables have a positive and significant effect on purchasing decisions. The regression coefficient of variable lifestyle is 6.916 and the significance is 0.000 . Thus, the hypothesis in this study which states that lifestyle has a positive and significant effect on the purchase decision of Fladeo products in Basko Grand Mall, accepted.
\end{abstract}

Keywords: Lifestyle and Purchase Decision.

\section{PENDAHULUAN}

Pada era pemasaran modern saat ini, jumlah merek dan produk yang bersaing dalam pasar semakin banyak sehingga konsumen memiliki ragam pilihan dan alternatif produk dan jasa yang dapat memenuhi kebutuhannya dan berhak memilih sesuai dengan apa yang konsumen inginkan.

Pengaruh teknologi canggih, seperti internet dan saluran tv satelit, memudahkan seseorang memperoleh informasi yang luas dan cepat, termasuk mengenai mode. Konsumen didorong untuk menyesuaikan diri dengan tren yang berlaku saat itu dan menghindar dari sebutan ketinggalan mode.

Gaya hidup (lifestyle) merupakan salah satu indikator dari faktor pribadi yang turut berpengaruh terhadap perilaku konsumen dan keputusan pembelian.

Bagi masyarakat high income berbelanja sudah menjadi lifestyle mereka, mereka akan rela mengorbankan sesuatu demi mendapatkan produk yang mereka senangi. Basko Grand Mall menjadi referensi fashion trend di Kota Padang sebagai pilihan konsumen berbelanja dan liburan bersama keluarga.

Keputusan pembelian adalah tindakan dari konsumen untuk mau membeli atau tidak terhadap produk (Kotler, P \& Keller, 2002). Dari berbagai faktor yang mempengaruhi konsumen dalam melakukan pembelian suatu produk atau jasa, biaya konsumen dalam melakukan 
pembelian suatu produk atau jasa, biasanya konsumen selalu mempertimbangkan kualitas, harga dan sudah yang dikenal oleh masyarakat sebelum konsumen memutuskan untuk membeli.

Merek Fladeo kategori sepatu telah masuk dalam Top Brand Index dan mendapatkan posisi pertama, ini membuktikan bahwa merek Fladeo paling banyak diminati para konsumen. Sedangkan di Basko Grand Mall Padang penjualan sepatu Fladeo Ladies dan Fladeo Mens mengalami penurunan persemesternya ini membuktikan bahwa semakin menurunnya minat konsumen Basko Grand Mall Padang untuk membeli sepatu Fladeo Ladies dan Fladeo Mens.

Menurunnya minat pengunjung di Basko Grand Mall Padang sepatu merek Fladeo Ladies dan Fladeo Mens karena adanya faktor persaingan begitu ketatnya persaingan yang terjadi di Basko Grand Mall Padang karena banyak merek - merek sepatu terkenal yang ditempatkan dalam lokasi yang sama hanya dipisahkan dengan rak rak yang bertuliskan merek sepatu tersebut. Fladeo telah menyediakan jenis dan model menarik sesuai dengan perkembangan fashion dan Fladeo sering kali menyuguhkan program menarik seperti adanya diskon dan buy one get one, diskon yang diberikandari $10 \%$ hingga $70 \%$. Dengan seringkali menyuguhkan program menarik tersebut seharusnya sepatu merek Fladeo bisa meningkatkan penjualannya tetapi kenyataannya persemester mengalami penurunan. Ini membuat Fladeo harus mengevaluasi strategi bersaingnya untuk meningkatkan penjualannya.
Penelitian ini berusaha untuk mengkaji fakto-faktor prilaku yang ada di diri konsumen yang meliputi sifat kepribadian (personality trait)s, keterlibatan berbelanja (fashion involvement), nilai berbelanja (hedonic shopping value) dan prilaku keputusan pembelian (impulse buying behavior) pada merek sepatu Fladeo.

Penelitian ini sudah pernah dilakukan oleh Deasy Purnama Sari yang meneliti tentang pengaruh lifestyle, efek komunitas dan fitur produk terhadap keputusan brand switching smartphone blackberry ke merek lain menyimpulkan bahwa seluruh variabel independen, yaitu lifestyle (X1), efek komunitas (X2), dan fitur produk (X3) secara parsial masing - masing memiliki pengaruh yang positif dan signifikan terhadap variabel dependen keputusan brand switching (Y).

Berdasarkan uraian di atas, maka penulis tertarik untuk melakukan penelitian mengambil judul 'Pengaruh Lifestyle Terhadap Keputusan Pembelian Sepatu Merek Fladeo di Basko Grand Mall Padang".

\section{LANDASAN TEORI}

Lifestyle (Gaya Hidup)

\section{Pengertian Gaya Hidup}

(Nugroho, 2003) mendenifisikan gaya hidup secara luas sebagai cara hidup yang diidentifikasi oleh bagaimana orang menghabiskan waktu mereka (aktifitas) apa yang mereka anggap penting dalam lingkungannya (keterkaitan) dan apa yang mereka perkirakan tentang diri mereka sendiri dan dunia sekitarnya.

Berdasarkan keterangan diatas gaya hidup dalam penelitian ini merupakan pola hidup masyarakat di 
Kota padang yang menentukan bagaimana pola seseorang memilih untuk menggunakan waktu, uang dan energi dan merefleksikan nilai - nilai, rasa dan kesukaannya akan sebuah merek. Gaya hidup cendrung mengklasifikasikan konsumen berdasarkan variabel-variabel yaitu aktifitas, interest (minat), dan pendapat atau pandangan.

Faktor-faktor yang Memengaruhi Lifestyle (Gaya Hidup)

Amstrong (dalam Nugraheni, 2003) menyatakan bahwa faktor-faktor yang mempengaruhi gaya hidup seseorang ada 2 faktor yaitu faktor yang berasal dari dalam diri individu (internal) dan faktor yangberasal dari luar (eksternal).

Faktor internal terdiri dari :

1. Sikap

2. Pengalaman dan pengamatan

3. Kepribadian

4. Konsep diri

5. Motif

6. Persepsi

Menurut Nugraheni (2003) adapun faktor eksternal terdiri dari :

1. Kelompok referensi

2. Keluarga

3. Kelas sosial

4. Kebudayaan

\section{KEPUTUSAN PEMBELIAN}

\section{Pengertian Keputusan Pembelian}

Keputusan pembelian merupakan kegiatan indivudu yang secara langsung terlibat dalam pengambilan keputusan untuk melakukan pembelian terhadap suatu produk yang di tawarkan oleh penjual. Pengertian keputusan pembelian, menurut (Kotler \& Amstrong, 2001) adalah tahap dalam proses pengambilan keputusan pembeli dimana konsumen benarbenar membeli. Pengambilan keputusan merupakan suatu kegiatan individu yang secara langsung terkibat dalam mendapatkan dan mempergunakan barang yang ditawarkan.

Faktor - Faktor yang Mempengaruhi Keputusan Pembelian Konsumen

Menurut (Kotler, P \& Armstrong, 2008) perilaku keputusan pembelian konsumen dipengaruhi oleh empat faktor, diantaranya sebagai berikut:

Faktor Budaya

1. Faktor Sosial

2. Faktor Pribadi

3. Faktor Psikologis

Indikator Keputusan Pembelian Hsu dan Chang 2003, dalam (Setyaji, 2008) mengemukakan indikator untuk mengukur keputusan pembelian sebagai berikut :

1.Keinginan untuk menggunakan produk

2.Keinginan untuk membeli produk

3.Memprioritaskan pembelian suatu produk

4.Kesediaan untuk berkorban (waktu, biaya, dan tenaga) untuk mendapatkan suatu produk.

Hipotesis

H1 : Diduga lifestyle berpengaruh signifikan dan positif terhadap keputusan pembelian sepatu merek Fladeo di Basko Grand Mall Padang.

\section{Kerangka Konseptual}

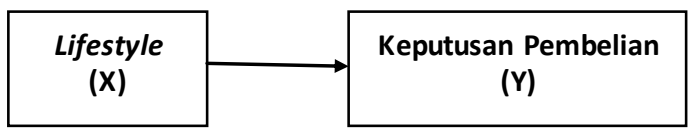

\section{METODE PENELITIAN \\ Jenis Penelitian}

Berdasarkan masalah yang akan diteliti pada penelitian ini maka jenis 
penelitian ini adalah penelitian kuantitatif. Penelitian kuantitatif yaitu pencarian data atau informasi dari realitas permasalahan yang ada dengan mengacu pada pembuktian konsep atau teori yang digunakan.

Objek Penelitian. Penelitian ini dilakukan pada konsumen Matahari Departmen Store Basko Grand Mall Padang.

\section{Populasi dan Sampel \\ Populasi}

Menurut (Sugiyono, 2008) "Populasi adalah wilayah generalisasi terdiri atas obyek/subyek yang mempunyai kualitas dan karakteristik tertentu, ditetapkan oleh peneliti untuk dipelajari dan kemudian ditarik kesimpulan". Populasi dalam penelitian ini adalah konsumen sepatu Fladeo yang pernah berbelanja di Basko Grand Mall Padang.

\section{Sampel}

Jumlah sampel yang dalam penelitian ini adalah 100 orang.

\section{Jenis dan Sumber Data}

Jenis Data

1. Data Kualitatif

2. Data Kuantitatif

\section{Sumber Data}

1. Data Primer

2. Data Sekunder

\section{Teknik Pengumpulan Data}

1. Observasi

2. Kuesioner

3. Wawancara

4. Studi Pustaka

\section{Uji Validitas dan Reabilitas}

1. Uji Validitas

Uji validitas adalah suatu uji statistik yang digunakan untuk mengetahui apakah instrumen (angket/kusioner) yang digunakan untuk mengambil data penelitian yang digunakan layak atau tidak dipergunakan untuk mengambil data yang selanjutnya digunakan untuk pengambilan data ang selanjutnya digunakan untuk pengambilan keputusan dalam penelitian. Menurut (Sugiyono, 2009) instrumen yang valid berarti alat ukur yang digunakan untuk mendapatkan data (mengukur) itu valid.

2. Uji Reabilitas

Nugroho (2005) menyatakan bahwa reliabilitas suatu konstruk variabel dikatakan baik jika memiliki nilai Cronbach's Alpha $>0,60$. Semakin dekat cronbach's alpha dengan 1, semakin tinggi keandalan konsistensi internal (Sekaran, 2006).

Analisis Deskriptif

Analisa ini bermaksud untuk menggambarkan karakteristik masingmasing variabel penelitian. (Arikunto, 2006) menyatakan bahwa kriteria nilai tingkat capaian responden TCR dapat.

Persentase pencapaian kriteria :

90T\%-100\% : sangat baik

$80 \%-89,99 \% \quad$ : baik

$65 \%-79,99 \% \quad$ : cukup baik

$55 \%-64,99 \% \quad$ : kurang baik

$0 \%-54,99 \% \quad$ : tidak baik

\section{Uji Asumsi Klasik}

Uji Normalitas

Menurut (Ghozali, 2011) uji normalitas adalah uji yang digunakan untuk melihat apakah dalam regresi, variabel dependen dan variabel independen atau keduanya mempunyai distribusi normal atau tidak. Model regresi yang baik adalah apakah distribusi normal atau tidak.

Analisa Regresi Linear Sederhana Analisa ini dimaksudkan untuk mengetahui besarnya pengaruh variabel bebas terhadap variabel 
terikat, dimana tujuan menggunakan analisa regresi sederhana pada penelitian ini adalah untuk mengetahui pengaruh lifestyle terhadap keputusan pembelian sepatu merek Fladeo di Basko Grand Mall Padang sebagai berikut :

$$
\mathrm{Y}=\mathrm{a}+\mathrm{bx}
$$

Dimana :

$\mathrm{Y}=$ keputusan pembelian

$\mathrm{a}=$ bilangan konstanta

$\mathrm{b}=$ koefisien regresi

$\mathrm{x}=$ lifestyle

Uji Hipotes is

\section{Uji Hipotes is (Uji T)}

Menurut (Sugiyono, 2007) dasar penggambilan keputusan untuk pengujian hipotesis adalah :

a. Jika nilai signifikan < $(0,50)$ maka terdapat pengaruh yang signifikan atau berarti dari variabel bebas terhadap variabel terikat (Hipotesis alternatif diterima).

b. Jika nilai signifikan $>(0,50)$ maka tidak terdapat pengaruh yang tidak signifikan atau tidak berarti dari variabel bebas terhadap variabel terikat.

Koefisien Determinasi $\left(\mathbf{R}^{\mathbf{2}}\right)$

Analisis determinan

dimaksudkan untuk mengetahui tingkat ketepatan paling baik dalam analisis regresi, dimana hal yang ditunjukan oleh besarnya koefisien determinasi $\left(\mathrm{R}^{2}\right)$ antara nol (0) dan (1).

\section{HASIL PENELITIAN DAN PEMBAHASAN}

Gambaran Umum Perusahaan

Fladeo didirikan oleh Onnes Kamil dengan nama PT Sabang Mandiri abadi. Saat ini, produk Fladeo tersebar di 145 dari total 146 gerai Matahari Department Store milik Group Lippo. Selain itu,
Fladeo memiliki 53 gerai sendiri yang tersebar di berbagai kota di Nusantara.

\section{Gambaran Umum Responden Berdasarkan Jenis Kelamin \\ Tabel 4.1.} Karakteristik konsumen

Berdasarkan Jenis Kelamin

\begin{tabular}{|c|c|c|c|}
\hline No & $\begin{array}{c}\text { Umur } \\
\text { (Tahun) }\end{array}$ & $\begin{array}{c}\text { Jumlah } \\
\text { (Orang) }\end{array}$ & Persentase \\
\hline 1 & Pria & 64 & $64 \%$ \\
\hline 2 & Wanita & 36 & $36 \%$ \\
\hline \multicolumn{2}{|c|}{ Jumlah } & 100 & $100 \%$ \\
\hline
\end{tabular}

Sumber: Data Primer 2018 (Diolah)

Gambaran Umum Responden
Berdasarkan Usia

Tabel 4.2.

Karakteristik konsumen

Berdasarkan Usia

Sumber: Data Primer 2018 (Diolah)

Gambaran Responden Berdasarkan Jenis Pendidikan

Tabel 4.3

\begin{tabular}{|l|l|l|l|}
\hline No & $\begin{array}{l}\text { Umur } \\
\text { (Tahun) }\end{array}$ & $\begin{array}{l}\text { Jumlah } \\
\text { (Orang) }\end{array}$ & Persentase \\
\hline 1 & $<18$ & 15 & $15 \%$ \\
\hline 2 & $19-30$ & 42 & $42 \%$ \\
\hline 3 & $31-40$ & 25 & $25 \%$ \\
\hline 6 & $>40$ & 18 & $18 \%$ \\
\hline \multicolumn{2}{|l}{ Jumlah } & 100 & $100 \%$ \\
\hline
\end{tabular}

Karakteristik Konsumen

Berdasarkan Jenis Pendidikan

\begin{tabular}{|l|l|l|l|}
\hline No & $\begin{array}{l}\text { Pendap } \\
\text { atan }\end{array}$ & $\begin{array}{l}\text { Jumlah } \\
\text { (Orang) }\end{array}$ & Persentase \\
\hline 1 & SMA & 32 & $27 \%$ \\
\hline 2 & S1 & 48 & $48 \%$ \\
\hline 3 & S2 & 15 & $15 \%$ \\
\hline 4 & S3 & 5 & $5 \%$ \\
\hline \multicolumn{2}{|l}{ Jumlah } & 100 & $100 \%$ \\
\hline
\end{tabular}

Sumber: Data Primer 2018 (Diolah) 
Gambaran Umum Responden

Berdasarkan Pekerjaan

Tabel 4.4

Karakteristik Konsumen

Berdasarkan Pekerjaan

\begin{tabular}{|l|l|l|l|}
\hline No & Pekerjaan & $\begin{array}{l}\text { Jumlah } \\
\text { (Orang) }\end{array}$ & Persentase \\
\hline 1 & $\begin{array}{l}\text { Pelajar/Ma } \\
\text { hasiswa }\end{array}$ & 32 & $32 \%$ \\
\hline 2 & PNS & 15 & $15 \%$ \\
\hline 3 & $\begin{array}{l}\text { Karyawan } \\
\text { Swasta }\end{array}$ & 17 & $17 \%$ \\
\hline 4 & $\begin{array}{l}\text { Wiraswast } \\
\text { a }\end{array}$ & 18 & $18 \%$ \\
\hline 5 & Lain-lain & 18 & $18 \%$ \\
\hline Jumlah & 100 & $100 \%$ \\
\hline
\end{tabular}

Sumber: Data Primer 2018 (Diolah)

Variabel Lifestyle

Tabel 4.5

Hasil Uji Validitas Variabel Life Style

\begin{tabular}{|c|c|c|c|c|}
\hline No & Pertanyaan/Indikator & $\mathbf{r}$ bitung & $\mathrm{r}$ tabel & Ket \\
\hline 1. & $\begin{array}{l}\text { Saya mengsunakan sepatu Fladeo } \\
\text { untuk. ke kantor, sekolah, dan } \\
\text { buliah. }\end{array}$ & 0,698 & 0,30 & Valid \\
\hline 2. & $\begin{array}{l}\text { Saya mengsunakan sepatu Fladeo } \\
\text { untuk pergi berbelanja. }\end{array}$ & 0,702 & 0,30 & Valid \\
\hline 3. & $\begin{array}{l}\text { Saxa membeli gepatu Fladeo barena } \\
\text { desainnxa menarik }\end{array}$ & 0,733 & 0,30 & Valid \\
\hline 4. & $\begin{array}{l}\text { Sepatu FladeQ membantr } \\
\text { penampilan saxa dalam beraktifitas. }\end{array}$ & 0,592 & 0,30 & Valid \\
\hline 5. & $\begin{array}{l}\text { Saya tertarik dengan sepato Fladeo } \\
\text { karena tahan lama. }\end{array}$ & 0,615 & 0,30 & Valid \\
\hline 6. & $\begin{array}{l}\text { Saxa membeli gepatu Fladea barena } \\
\text { kenvamanan gast memalkai sepatu. }\end{array}$ & 0,410 & 0,30 & Valid \\
\hline 7. & $\begin{array}{l}\text { Pada saat saxa memakai sepato } \\
\text { Eladeq kepercaxasa diri saxa } \\
\text { bertambah. }\end{array}$ & 0,518 & 0,30 & Valid \\
\hline 8. & $\begin{array}{l}\text { Sava tertarik dengan sepatu Fladeo } \\
\text { karema produk berkualitas. }\end{array}$ & 0,548 & 0,30 & Valid \\
\hline 9. & $\begin{array}{l}\text { Harga sepatu Fladeo mencerminkan } \\
\text { bualitas produk. }\end{array}$ & 0,445 & 0,30 & Valid \\
\hline 10. & $\begin{array}{l}\text { Harga sepatu Fladeq lebih } \\
\text { teriangkau dari pada sepatu lainnwa. }\end{array}$ & 0,431 & 0,30 & Valid \\
\hline 11. & $\begin{array}{l}\text { Saxa merabeli gepatu Fladea karena } \\
\text { banyak yariagi dari produk tersebut. }\end{array}$ & 0,418 & 0,30 & Valid \\
\hline 12. & $\begin{array}{l}\text { Sava membeli sepatu Fladea barena } \\
\text { mengikuti kelompok pergaulan } \\
\text { saxa. }\end{array}$ & 0,471 & 0,30 & Valid \\
\hline 13. & $\begin{array}{l}\text { Saya melakukan pembelian sepato } \\
\text { Fladea di Basko Grand Mall karena. } \\
\text { rekomendasi dari teman atau rekan } \\
\text { keria saxa }\end{array}$ & 0,698 & 0,30 & Valid \\
\hline 14. & $\begin{array}{l}\text { Sava membeli sepatu Fladeo di } \\
\text { Baske Grand Mall karena lokasi } \\
\text { penjualan sepatu mudah dijanglau. }\end{array}$ & 0,702 & 0,30 & Valid \\
\hline 15. & $\begin{array}{l}\text { Sava memneli sepato Fladeo di } \\
\text { Basko Grand Mall barena produk } \\
\text { mudah dicari. }\end{array}$ & 0,733 & 0,30 & Valid \\
\hline
\end{tabular}

Uji Validitas Variabel Keputusan Pembelian

\section{Uji Realibilitas}

\begin{tabular}{|c|c|c|c|c|}
\hline $\mathrm{N}_{0}$ & Pertanyaan/Indikator & r hitumg & r tabel & Ket \\
\hline 1. & 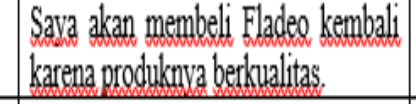 & 0.482 & 0,30 & Valid \\
\hline 2. & 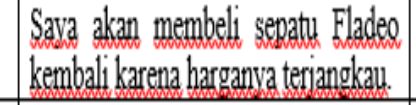 & 0.530 & 0,30 & Valid \\
\hline 3. & $\begin{array}{l}\text { Sava akan membeli sepatu Fladeo } \\
\text { kembali karma ivkantya sangat } \\
\text { menarik. }\end{array}$ & 0.311 & 0,30 & Valid \\
\hline 4. & 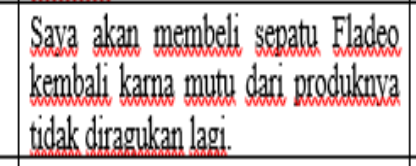 & 0.520 & 0,30 & Valid \\
\hline 5. & $\begin{array}{l}\text { Sava akan membeli sepatt Fladea } \\
\text { kembalikarenatersediaditoko- toko. }\end{array}$ & 0.553 & 0,30 & Valid \\
\hline 6. & $\begin{array}{l}\text { Sava memutuskan membeli di Basko } \\
\text { Grand Mall karena terdorong ingin } \\
\text { membeli produk. }\end{array}$ & 0.375 & 0,30 & Valid \\
\hline 7. & $\begin{array}{l}\text { Sava memutuskan membeli di Basko } \\
\text { Grand Mall karema produk yang di } \\
\text { jual sesuai dengan harapan sava. }\end{array}$ & 0.410 & 0,30 & Valid \\
\hline 8. & $\begin{array}{l}\text { Menund sava Basko Gand Mall } \\
\text { alternatif ytama dalam membeli } \\
\text { sepatutu Fladeo. }\end{array}$ & 0.555 & 0,30 & Valid \\
\hline 9. & $\begin{array}{l}\text { Tika membutuhkan sepatu Fladea } \\
\text { saya akan membeli di Basko Grand } \\
\text { Mall. }\end{array}$ & 0.514 & 0,30 & Valid \\
\hline 10. & $\begin{array}{l}\text { Sepatu Fladeo memberikan kepuasasn } \\
\text { bagi sava. }\end{array}$ & 0.379 & 0,30 & Valid \\
\hline
\end{tabular}


Tabel 4.7

Uji Reliabilitas

\begin{tabular}{|l|l|l|l|l|}
\hline No & Variabel & Cronbach's & Alpha & \\
Alpha & & Keterangan \\
\hline 1. & Liffe Styje (X) & 0,899 & 0,60 & Reliabel \\
\hline 2. & Keputusand Pembelian (I) & 0,792 & 0,60 & Reliabel \\
\hline
\end{tabular}

\section{Analisis Statistik Deskriptif}

Tabel 4.8

Persentasi Pencapaian Kriteria

\begin{tabular}{|c|c|c|}
\hline NO & $\begin{array}{c}\text { Presentase } \\
\text { Pencapain }\end{array}$ & Kriteria \\
\hline 1 & $90 \%-100 \%$ & Sangat baik \\
\hline 2 & $80 \%-$ & Baik \\
& $89,99 \%$ & \\
\hline 3 & $65 \%-$ & Cukup baik \\
& $79,99 \%$ & \\
\hline 4 & $55 \%-$ & Kurang baik \\
& $64,99 \%$ & \\
\hline 5 & $0 \%-54,99 \%$ & Tidak baik \\
\hline
\end{tabular}

Tabel 4.9

Distribusi Frekuesi Life Style

\begin{tabular}{|l|l|l|l|}
\hline No & Pertanyaan/Indikator & TCR & Ket \\
\hline 1. & $\begin{array}{l}\text { Saya menggunakan sepatu Fladeo } \\
\text { untuk ke kantor, sekolah, dan kuliah. }\end{array}$ & Cukup Baik \\
\hline 2. & $\begin{array}{l}\text { Saya menggunakan sepatu Fladeo } \\
\text { untuk pergi berbelania. }\end{array}$ & 80,8 & Baik \\
\hline 3. & $\begin{array}{l}\text { Saya membeli sepatu Fladeo karena } \\
\text { desainnya menarik. }\end{array}$ & 81 & Baik \\
\hline 4. & $\begin{array}{l}\text { Sepatu Fladeo membantu penampilan } \\
\text { saya dalam beraktifitas. }\end{array}$ & 79,8 & Cukup Baik \\
\hline 5. & $\begin{array}{l}\text { Saya tertarik dengan sepatu Fladeo } \\
\text { karena tahan lama. }\end{array}$ & 84 & Baik \\
\hline 6. & $\begin{array}{l}\text { Saya membeli sepatu Fladeo karena } \\
\text { kenyamanann saat memakai sepatu. }\end{array}$ & 82,2 & Baik \\
\hline 7. & $\begin{array}{l}\text { Pada saat saya memakai sepatu } \\
\text { Fladeo kepercayaan diri saya } \\
\text { bertambah. }\end{array}$ & Baik \\
\hline 8. & $\begin{array}{l}\text { Saya tertarik dengan sepatu Fladeo } \\
\text { karena produk berkualitas. }\end{array}$ & 82 & Baik \\
\hline 9. & $\begin{array}{l}\text { Harga sepatu Fladeo mencerminkan } \\
\text { kualitas produk. }\end{array}$ & 80 & Baik \\
\hline 10. & $\begin{array}{l}\text { Harga sepatu Fladeo lebih terjangkau } \\
\text { dari pada sepatu lainnya. }\end{array}$ & 81 & Baik \\
\hline 11 & $\begin{array}{l}\text { Saya membeli sepatu Fladeo karena } \\
\text { banyak variasi dari produk tersebut. }\end{array}$ & 85,4 & Baik \\
\hline 12. & Saya membeli sepatu Fladeo karena & 80,4 & Baik \\
\hline
\end{tabular}

Sumber: Data Primer 2018 (Diolah)
Tabel 4.10

Distribusi Frekuensi Variabel

Keputusan Pembelian 


\begin{tabular}{|c|c|c|c|}
\hline $\mathrm{N}_{0}$ & Pertanvaan/Indikator & TCR & Ket \\
\hline 1. & $\begin{array}{l}\text { Sava akan membeli Fladeo } \\
\text { kembali karena produknva } \\
\text { berkualitas. }\end{array}$ & 75,4 & Cukup Baik \\
\hline 2. & $\begin{array}{l}\text { Sava akan membeli sepatu } \\
\text { Fladeo kembali karena } \\
\text { harganva teriangkau. }\end{array}$ & 75,4 & Cukfup Baik \\
\hline 3. & $\begin{array}{l}\text { Sava akan membeli sepatu } \\
\text { Fladeo kembali karna iklannvia } \\
\text { sangat menarik. }\end{array}$ & 82,4 & Baik \\
\hline 4. & $\begin{array}{l}\text { Sava akan membeli sepatu } \\
\text { Fladeo kembali karna mutu dari } \\
\text { produknva tidak diragukan lagi. }\end{array}$ & 79 & Cukup Baik \\
\hline 5. & $\begin{array}{l}\text { Sava akan membeli sepatth } \\
\text { Fladeo kembali karena tersedia } \\
\text { ditoko - toko. }\end{array}$ & 79,6 & Cukfup Baik \\
\hline 6. & $\begin{array}{l}\text { Sava memutuskan membeli di } \\
\text { Baske Grand Mall karena } \\
\text { terdorong ingin membeli } \\
\text { produk. }\end{array}$ & 80 & Baik \\
\hline 7. & $\begin{array}{l}\text { Sava memutuskan membeli di } \\
\text { Basko Grand Mall karena } \\
\text { produk yang di jual sesuai } \\
\text { dengan harapan sava. }\end{array}$ & 83,8 & Baik \\
\hline 8. & $\begin{array}{l}\text { Menurut sava Basko Gand Mall } \\
\text { alternatif ytama dalam membeli } \\
\text { sepatu Fladeo. }\end{array}$ & 80,2 & Baik \\
\hline 9. & $\begin{array}{l}\text { Jika membutuhkan sepatu } \\
\text { Fladeo sava akan membeli di } \\
\text { Basko Grand Mall. }\end{array}$ & 81,8 & Baik \\
\hline 10. & $\begin{array}{l}\text { Sepatu Fladeo memberikan } \\
\text { kepuasan bagi sava. }\end{array}$ & 80,4 & Baik \\
\hline
\end{tabular}

Sumber: Data Primer 2018 (Diolah)

Uji Asumsi Klasik

Uji Normalitas

Tabel 4.11

Uji Normalitas

One-Sample Kolmogorov-Smirnov Test

\begin{tabular}{|ll|l|}
\hline & & $\begin{array}{l}\text { Standardized } \\
\text { Residual }\end{array}$ \\
\hline Normal Parameters & \\
& & 100 \\
Most Extreme Differences & Mean & .0000000 \\
& Std. Deviation & .99493668 \\
& Absolute & .091 \\
Kolmogorov-Smirnov Z & Positive & .051 \\
Asymp. Sig. (2-tailed) & Negative & -.091 \\
\hline a. Test distribution is Normal. & & .912 \\
\hline
\end{tabular}

Sumber: Data Diolah Tahun 2018 (Diolah)

Analisis Regresi Linier Sederhana

Tabel 4.12

Hasil Analisis Regresi Sederhana
Coefficients $^{\mathrm{s}}$

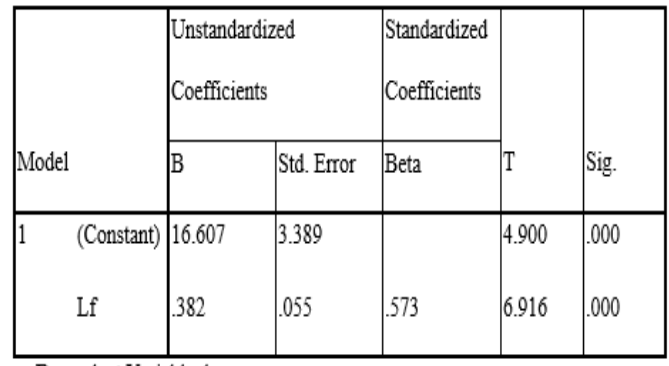

a. Dependent Variable: kp

Sumber: Data Primer 2018 (Diolah)

Dapat dilihat dari tabel 4.15. di atas maka dapat diketahui bahwa hasil dari persamaan regresi sebagai berikut:

$$
\begin{gathered}
\mathrm{Y}=\mathrm{a}+\beta 1 \mathrm{X}+\mathrm{e} \\
\mathrm{Y}=16,607+0,382 \mathrm{X}+\mathrm{e}
\end{gathered}
$$

Interpretasi persamaan di atas:

1. Nilai konstanta dari persamaan di atas adalah 16,607. Hal ini menunjukkan bahwa tanpa adanya pengaruh lifstyle, maka keputusan pembelian tetap sebesar 16,607.

2. Lifestyle (X) memiliki koefisien regresi positif sebesar 0,382, berarti lifestyle memiliki hubungan yang positif dengan keputusan pembelian. Hal ini menunjukkan jika lifestyle bertambah 1 satuan maka, keputusan pembelian bertambah sebesar 0,382 (38,2\%).

\section{Uji Hipotesis}

Uji T

Tabel 4.13

\section{Hasil Uji T}

Coefficients ${ }^{2}$

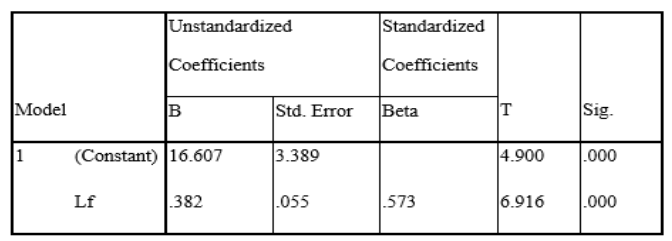

Sumber: Data Primer 2018 (Diolah)

Berdasarkan hasil analisa pada tabel 4.18, bahwa dengan tingkat signifikan menggunakan alfa 0,05 dan 
derajat kebebasan $(\mathrm{df})=(\mathrm{n}-\mathrm{k}-1)=100-$ $1-1=98$, dengan merujuk pada ttabel maka diperoleh t-tabel sebesar 1,6605. Variabel lifestyle mempunyai nilai $\mathrm{t}$ hitung 6,916>1,6605 dan tingkat signifikan sebesar $0,000<0,05$ memperhatikan hasil dari signifikan, maka dapat disimpulkan bahwa variabel lifestyle mempunyai pengaruh positif dan signifikan terhadap keputusan pembelian.

Uji Koefisien Determinasi ( $\mathbf{R}^{\mathbf{2}}$ )

Untuk mengukur koefisien determinasi berganda $\left(\mathrm{R}^{2}\right)$ untuk mengukur seberapa besar pengaruh variable independent terhadap variable dependen.

Tabel 4.14

Hasil Uji Koefisien Determinasi $\left(\mathbf{R}^{2}\right)$

Coefficients $^{\mathrm{a}}$

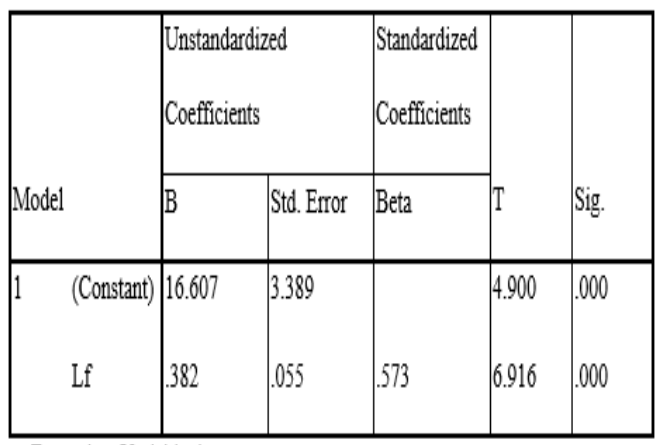

a. Dependent Variable: kp

Sumber: Data Primer 2018 (Diolah)

Pada tabel 4.14. di atas menunjukkan bahwa nilai koefisien Rsquare adalah sebesar 0,328, hal ini berarti $32,8 \%$ variabel keputusan pembelian dapat dijelaskan oleh variabel lifestyle sedangkan sisanya $(100 \%-32,8 \%=67,2 \%)$ dipengaruhi oleh variabel lain yang tidak ada di dalam penelitian ini yang terkait dengan keputusan pembelian seperti kualitas produk, harga, dan lain sebagainya. Angka koefisien korelasi (R) sebesar 0,573 menunjukkan bahwa hubungan antara variabel independen dengan variabel dependen adalah kuat karena memiliki nilai koefisien korelasi di atas 0,05 .

Pembahasan

Dari penelitian di atas menunjukkan bahwa variabel lifestyle mempunyai tingkat signifikan sebesar $0,000<0,05$. Memperhatikan hasil uji $\mathrm{t}$ ini, maka hipotesis yang menyatakan bahwa lifestyle mempunyai pengaruh positif dan signifikan terhadap keputusan pembelian sepatu merek Fladeo diterima. Hal ini menunjukkan bahwa lifestyle memiliki elemen yang positif akan memberikan suatu nilai bagi konsumen untuk melakukan keputusan pembelian. Semakin tinggi lifestyle maka dapat mempengaruhi konsumen untuk melakukan keputusan pembelian.

Hasil penelitian ini selaras dengan penelitian yang dilakukan oleh Adi (2015) dengan hasil penelitianya yaitu lifestyle memiliki pengaruh positif dan signifikan terhadap keputusan pembelian.

PENUTUP

Kesimpulan

Adapun kesimpulan dari penelitian ini adalah sebagai berikut:

1. Berdasarkan hasil penelitian dan pembahasan maka dapat ditarik kesimpulan variabel lifestyle mempunyai tingkat signifikansi sebesar $0,000<0,05$ dan memiliki nilai t-hitung sebesar $6,916>\mathrm{t}$ tabel. Memperhatikan hasil uji $\mathrm{t}$ test ini, maka hipotesis yang menyatakan bahwa variabel lifestyle mempunyai pengaruh positif dan signifikan terhadap 
2. keputusan pembelian sepatu merek Fladeo di Basko Grand Mall Padang.

3. Variabel lifestyle dapat menjelaskan variabel keputusan pembelian sebesar 32,8\%, sedangkan sisianya $67,2 \%$ dijelaskan oleh variabel lain yang terkait dengan keputusan pembelian yang tidak diteliti pada penelitian ini, seperti harga, merek, desain, dan lainnya.

\section{Saran}

Berdasarkan hasil penelitian ini, saran yang dapat disampaikan adalah sebagai berikut:

\section{DAFTAR PUSTAKA}

Fatharani, N. Lubis, and R. S. Dewi, "Pengaruh Gaya Hidup ( Life Style ), Harga ( Price ), dan Kelompok Referensi ( Reference Group ) terhadap Keputusan Pembelian Telepon Seluler Blackberry ( Studi Pada Mahasiswa Program S1 Angkatan 2009 Fakultas Ilmu Sosial dan Ilmu Politik Universitas Dipon," pp. 1-20, 2009.

K. Produk, B. Image, D. A. N. Life, and S. Terhadap, "Keputusan Pembelian Pakaian Wanita Di Mississippi Analysis of Product Quality , Brand Image and Life Style Towards Purchasing," vol. 3, no. 1, pp. 1096-1105, 2015.

K. Produk, B. Image, D. A. N. Life, and S. Terhadap, 'Keputusan Pembelian Pakaian Wanita Di Mississippi Analysis of
1. Bagi pihak sepatu merek Fladeo, untuk dapat meningkatkan kualitas produk dan inovasi produk agar produk Fladeo dapat diterima dan digunakan oleh semua kalangan.

2. Untuk peneliti selanjutnya dapat menggunakan variabel lain selain yang digunakan dalam penelitian ini untuk meneliti keputusan pembelian, karena selain variabelvariabel yang telah penulis gunakan masih terdapat variabelvariabel lain yang akan mempengaruhi keputusan pembelian.
Product Quality , Brand Image and Life Style Towards Purchasing," vol. 3, no. 1, pp. 1096-1105, 2015.

S. Susanto, "Membuat Segmentasi Berdasarkan Life Style ( Gaya Hidup )," pp. 1-6, 2003.

Arikunto, Prosedur Penelitian Suatu Pendekatan Praktik, Ed Revisi. Jakarta: PT. Rineka Cipta, 2006.

T. Widjaja, Lifestyle Marketing. Jakrata: Gramedia Pustaka Utama, 2009.

D. I. Samarinda, "Pengaruh Gaya Hidup dan Konsep Diri Terhadap Pengambilan Keputusan Konsumen Dalam Memilih Coffeeshop di Samarinda," pp. 36-43, 1945.

P. Sari, "Pengaruh Lifestyle, Efek 
Komunitas Dan Fitur Produk Terhadap Keputusan Brand Switching Smartphone Blackberry Ke Merek Lain," Pengaruh Lifestyle, Efek Komunitas Dan Fitur Prod. Terhadap Keputusan Brand Switch. Smartphone Blackberry Ke Merek Lain, no. 24, pp. 1-9.

\section{SATRIA, "Pengaruh Gaya Hidup Terhadap Keputusan Pembelian Handphone Merek Blackberry Di Kota Sungai Penuh Jambi."}

Kotler, P \& Armstrong, Prinsip Prinsip Pemasaran, 12th ed. Jakarta: Penerbit Erlangga, 2008.

Chriesmaya, "Pengaruh gaya hidup terhadap keputusan konsumen dalam memilih minimarket alfamart di malang," no. Chriesmaya, I. E. (n.d.). Pengaruh gaya hidup terhadap keputusan konsumen dalam memilih minimarket alfamart di malang, XI-XXX., pp. XIXXX.

Kotler, $\mathrm{P}$ \& Keller, Manajemen Pemasaran, 12th ed. Jakarta: Indeks, 2009.

Kotler \& Amstrong, Prinsip - Prinsip Pemasaran, I. Jakarta: Erlangga, 2001.

Marlius, D. (2017). Keputusan Pembelian Berdasarkan Faktor Psikologis Dan Bauran Pemasaran Pada PT. Intercom Mobilindo Padang. Jurnal
Pundi. Volume 1. No. 1. Hal. 57-66.

https://doi.org/10.31575/jp.v1

i1.9

Marlius, D. (2016). Pengaruh Bauran Pemasaran Jasa Terhadap Minat Nasabah Dalam Menabung Pada Bank Nagari Cabang Muaralabuh. https://doi.org/10.31227/osf.io /vdqgx

Nugraheni, "Perbedaan Kecenderungan Gaya Hidup Hedonis Remaja Ditinjau Dari Lokasi Tempat Tinggal," 2003.

Kotler, Manajemen Pemasaran, I dan II. PT. Indeks Kelompok Gramedia, 2005.

Prasetijo, Perilaku Konsumen, 1st ed. Yogyakarta: Andi, 2005.

Priyanti,Y. Susanti, F. Aziz, N. (2017). Minat Beli Konsumen Toko Sepatu Bata Dipasar Raya Padang Dilihat Dari Sikap Dan Iklan. Jurnal Pundi, Vol. 01, No. 02

Nugroho, Perilaku Konsumen (Konsep dan Implikasi Untuk Strategi dan Penelitian Pemasaran). Yogyakarta: Andi, 2003.

Susanti, F. (2015). Pengaruh Bauran Promosi Terhadap Keputusan Klien Dalam Memilih Radio Carano Sebagai Media Promosi Iklan. https://doi.org/10.31227/osf.io /b9ws7 